\title{
Patient Use and Experience With Online Access to Electronic Health Records in Norway: Results From an Online Survey
}

Paolo Zanaboni ${ }^{1}$, PhD; Per Egil Kummervold ${ }^{2}$, PhD; Tove Sørensen ${ }^{3}$, MSc; Monika Alise Johansen ${ }^{1}$, PhD

\author{
${ }^{1}$ Norwegian Centre for E-health Research, University Hospital of North Norway, Troms $\emptyset$, Norway \\ ${ }^{2}$ NORCE Norwegian Research Centre, Troms $\emptyset$, Norway \\ ${ }^{3}$ Helse Nord IKT, Troms $\varnothing$, Norway
}

\section{Corresponding Author:}

Paolo Zanaboni, PhD

Norwegian Centre for E-health Research

University Hospital of North Norway

PO Box 35

Troms $\varnothing$,

Norway

Phone: 4791554636

Email:paolo.zanaboni@ehealthresearch.no

\begin{abstract}
Background: The electronic health record (EHR) has been fully established in all Norwegian hospitals. Patient-accessible electronic health records (PAEHRs) are available to citizens aged 16 years and older through the national health portal Helsenorge.

Objective: This study aimed at understanding how patients use PAEHRs. Three research questions were addressed in order to explore (1) characteristics of users, (2) patients' use of the service, and (3) patient experience with the service.

Methods: We conducted an online survey of users who had accessed their EHR online at least once through the national health portal. Patients from two of the four health regions in Norway were invited to participate. Quantitative data were supplemented by qualitative information.

Results: A total of 1037 respondents participated in the survey, most of whom used the PAEHR regularly $(305 / 1037,29.4 \%)$ or when necessary $(303 / 1037,29.2 \%)$. Service utilization was associated with self-reported health, age, gender, education, and health care professional background. Patients found the service useful to look up health information $(687 / 778,88.3 \%)$, keep track of their treatment $(684 / 778,87.9 \%)$, prepare for a hospital appointment $(498 / 778,64.0 \%)$, and share documents with their general practitioner $(292 / 778,37.5 \%)$ or family $(194 / 778,24.9 \%)$. Most users found it easy to access their EHR online (965/1037, 93.1\%) and did not encounter technical challenges. The vast majority of respondents $(643 / 755,85.2 \%)$ understood the content, despite over half of them acknowledging some difficulties with medical terms or phrases. The overall satisfaction with the service was very high $(700 / 755,92.7 \%)$. Clinical advantages to the patients included enhanced knowledge of their health condition $(565 / 691$, $81.8 \%)$, easier control over their health status $(685 / 740,92.6 \%)$, better self-care $(571 / 653,87.4 \%)$, greater empowerment $(493 / 674$, $73.1 \%)$, easier communication with health care providers (493/618, 79.8\%), and increased security $(655 / 730,89.7 \%)$. Patients with complex, long-term or chronic conditions seemed to benefit the most. PAEHRs were described as useful, informative, effective, helpful, easy, practical, and safe.
\end{abstract}

Conclusions: PAEHRs in Norway are becoming a mature service and are perceived as useful by patients. Future studies should include experimental designs focused on specific populations or chronic conditions that are more likely to achieve clinically meaningful benefits. Continuous evaluation programs should be conducted to assess implementation and changes of wide-scale routine services over time.

(J Med Internet Res 2020;22(2):e16144) doi: 10.2196/16144

\section{KEYWORDS}

electronic health records; patient online access; patient portals; service utilization; satisfaction; patient empowerment 


\section{Introduction}

\section{Background}

With the rapid rise in the adoption of patient portals, many patients are gaining access to their personal health information online for the first time [1] and expecting extensive access to their health documents [2]. The vast majority of patients endorse the concept of patient-accessible medical records [3]. However, despite the fact that most patients know that they have the legal right to access their records and are interested in what is written, only a minority of them actually access their records [4,5].

An electronic health record (EHR) is the electronic collection of clinical data and can include clinical assessments, laboratory results, radiology findings, nursing documentation, allergy information, medication information, and discharge letters [6]. Patient-accessible electronic health records (PAEHRs) [7] are online services providing patients the ability to view and sometimes edit or comment on their EHR made available by their health care providers [8,9]. Online access to the EHR can be offered to patients, relatives, or other informal carers by health care organizations or on a national scale [6]. PAEHRs can potentially enhance the provision of patient-centered care $[10,11]$, making it easier for most people to understand their health status and health care processes [12]. This may also enable patients to more effectively self-manage and take the lead in consultations [8].

Patients' increasing demands for medical information, the digitization of health records, and the fast spread of internet access form the basis for introducing new digital health services [13]. At the same time, initiatives to enable patients to access and understand their EHR are gathering momentum [12]. The number and type of documents that are made available online vary between and within countries, making it challenging for patients who visit different health facilities [14]. A recent cross-national comparison reported implementation of PAEHR services in 10 different countries, including Nordic countries, European countries, and non-European countries [15]. In Sweden, access by patients to their EHR was introduced in a pilot county in November 2012 [13]. The PAEHR service has been recently reported to be used nationwide by 19 of the 21 county councils [16], overall with positive experiences for patients [17]. A national patient survey showed that the main reason for use was to gain an overview of one's health status, and that laboratory results were the most important information to access [18]. The Open Notes pilot study provided patients at three large US health systems access to primary care notes online $[4,19]$. The great majority of patients reported better understanding of their medical conditions and recall of their treatment plans [20]. In a recent large-scale survey of nearly 23,000 patients who used Open Notes, patients rated note reading as very important for helping take care of their health, feeling in control of their care, and remembering the plan of care [21]. Only a few patients were very confused or more worried after reading notes [21]. The My HealtheVet pilot program offered by the US Department of Veterans Affairs was an early prototype allowing patients to view and download content of their EHR, including clinical notes, laboratory tests, and imaging reports [22]. Users were highly satisfied with the service, appreciated the ability to easily access their own EHR, and considered it beneficial to their health and care [23]. In 2012, Australia launched a personally controlled EHR designed around the needs of consumers and aimed at becoming a system-wide activity [24].

\section{Online Access to Electronic Health Records in Norway}

All citizens and residents in Norway have the right to access their health records created by a health care provider (eg, hospital, general practitioner [GP] office, dentist) [25]. The procedure has been that patients could request a copy of their health records on paper or $\mathrm{CD}$ from each health care provider for a fee. Upon request, patients are entitled to a brief and simple oral explanation of medical terms. Patients also have the right to know who has accessed or received information from their health records. As a rule, patients have the right to access their entire health record. According to the Patients' Rights Act, a patient may be denied access to parts of their health record if this is absolutely necessary in order to avoid endangering the patient's life or causing serious damage to the patient's health or if access is clearly inadvisable out of consideration for persons close to the patient. A representative of the patient is entitled to obtain the information that the patient is denied access to.

The EHR is fully established by all Norwegian hospitals. The national health portal Helsenorge [26] was established in 2011 to accommodate digital patient services and secure access to health information after secure log-in [27]. In 2012, a white paper, One Citizen-One Record, stated that patients should have online access to their EHR [28]. PAEHR is now offered to citizens aged 16 years and older and to those with parental responsibility for children under the age of 12 years. Online access to the EHR is not yet available for children aged between 12 and 16 years. By October 2016, PAEHR was offered by two (Northern Norway and Western Norway) of the four health regions in Norway through the national portal. Through the service patients can access, read, and download their health records from hospitals (ie, referrals, outpatient visit summaries, clinical notes, discharge letters). Not all documents are available digitally. In Northern Norway, most documents generated after September 2015 are available online, while Western Norway offers online access to documents generated since March 2016. Patients in Northern Norway also can obtain electronic access to older documents upon request. If a citizen has never been to the hospital, no documents appear in the PAEHR. There may also be other reasons why not all of the information is digitally available. Documents can be in a format that is currently not supported (eg, x-rays) or displayed (eg, in the Android app). Some information may not be made available for legal or professional reasons. At the moment, only EHRs from hospitals are available digitally, while health records from GPs, dentists, and other specialists are not. Patients are not notified when new documents are signed and digitally available.

Through the national health portal patients can also retrieve the access log, which shows a list of all those who have accessed their EHR for health or administrative reasons. Use of the PAEHR is not mandatory, and patients can choose not to have 
their EHR accessible online. The EHR consists of many different types of documents, some of which have been manually scanned. Patients can report errors in the documents to the responsible health care provider so that they can be corrected as soon as possible.

\section{Study Aim}

To date, only a few studies have been performed on large-scale implementation of a national PAEHR and its use by citizens. Evaluations of digital health services are often done from a health care provider perspective, focusing on aspects that are considered important to health care professionals and decision makers. Experiences of evaluations from the perspective of the patients are still scarce [17]. Moreover, most published evaluations have been focused on primary care or office-based practices [29].

This study aimed at understanding how patients use online access to their EHRs through a survey consisting of quantitative data supplemented by qualitative information. In particular, three main research questions were addressed to explore (1) characteristics of the users, (2) patients' use of the service, and (3) patient experience with the service.

\section{Methods}

\section{Study Design}

We conducted an online survey of users who had activated their personal account at the national health portal and accessed their EHR online at least once. Only citizens with access to the service by October 2016 were invited to participate. These included citizens living in two health regions, Northern Norway and Western Norway. The survey was available after secure $\log$-in on the national health portal. All active users who accessed their EHR online received an invitation through a pop-up window with a brief description of the study and a link to the survey.

The online survey included questions regarding (1) background characteristics, (2) use of the service, and (3) experience with the service (Multimedia Appendix 1). Background characteristics of the users included information on the region in which they were located, gender, age, education level, health care professional background, access to the hospital in the previous year, and self-reported health [30] as defined by the World Health Organization [31]. Use of the service was explored through questions related to frequency of use, number of documents accessible digitally, main reasons for using the service, acquaintance with the service, contact with service support, and availability of older documents. Patient experience with PAEHRs was evaluated with a number of questions concerning ease of access, their opinion about content and features included in the service, its impact on health and treatment, security, overall satisfaction, and future use. Questions on background characteristics and use of the service were multiple choice with a number of alternatives ranging from 2 to 8 depending on the questions. Most of the questions concerning user experiences were scored on a 4-point Likert scale ( $1=$ strongly disagree, $2=$ disagree, $3=$ agree, $4=$ strongly agree). Respondents were allowed to skip a question by answering not applicable. Two open-ended questions were included so that respondents could provide additional information regarding their willingness to use the service in the future and whether they would recommend it to others. A third open-ended question was included at the end of the survey to collect additional comments provided by the users.

The online survey was developed by the Norwegian Centre for E-health Research in collaboration with the project implementing the PAEHR service in Northern Norway on behalf of the Northern Norway Regional Health Authority. The survey was published on the national portal by the Norwegian Directorate of eHealth. The link to the survey was available for a period of 4 weeks. All information collected through the survey was anonymous and not personally identifiable. Participation in the survey was based on consent wherein each respondent could choose not to answer the questionnaire. Ethics approval from the Regional Committees for Medical and Health Research Ethics was deemed not necessary according to the Health Research Act on medical and health research entered into force in Norway in 2009. The study was approved by the Data Protection Officer of the University Hospital of North Norway. The Checklist for Reporting Results of Internet E-Surveys (CHERRIES) was used to develop the survey and report its results [32]. The online survey was developed with the online data collection solution Questback Essentials, and its technical functionality was tested before being published.

\section{Data Analysis}

Respondents were analyzed by age according to the following groups: 16 to 24 years, 25 to 34 years, 35 to 44 years, 45 to 54 years, 55 to 64 years, and over 65 years. Population data for the year 2015 were provided by the Center for Clinical Documentation and Evaluation and used to compare the demographic characteristics of the respondents with the general population and patients receiving specialist health care. Participation and completion rates were not reported, as data on unique visitors were not available. The selection of respondents to this survey was assumed to be representative of those who actually used the service.

Data on patient use and experience with the service were summarized by descriptive statistics as well as by graphs. In the analysis of the questions concerning user satisfaction with the service, results were summarized by the proportion of respondents who agreed with a certain aspect (scores 3 and 4) and those who disagreed (scores 1 and 2). Possible variations in service utilization among respondents were explored by analyzing frequency of use (light users vs regular users) against patient characteristics. A Pearson Chi-square test was used to explore associations between the two categorical variables.

Qualitative data provided in the open text fields were subject to content analysis [33]. These open text fields were not mandatory. The information was provided only by those respondents who were willing to express additional comments about the service. These could include general statements, positive feedback, criticism, reports of technical problems, and suggestions for service improvements. Answers were stratified into positive, neutral, and negative. The content of these answers was analyzed by a multidisciplinary research team consisting 
of two authors. Codes were assigned to each comment. The coding labels were compared to find similarities in the interpretations of the content and resolve differences. The results were summarized around common themes. Qualitative data were used to support the results of the quantitative data. Comments providing good examples of patient opinions around the different themes are presented.

Data analysis was performed by NORCE Northern Research Centre and the Norwegian Centre for E-health Research. Data were extracted in Excel (Microsoft Corp) and further analyzed in SPSS Statistics version 25 (IBM Corp) and R version 3.4.2 (R Foundation for Statistical Computing).

\section{Results}

\section{Characteristics of the Users}

The online survey was available on the national portal from October 24, 2016, to November 21, 2016. In total, 1037 users answered the survey. Of these, 569 respondents $(54.9 \%)$ were from Western Norway, 395 respondents $(38.1 \%)$ were from
Northern Norway, and 73 respondents (7.0\%) had received health care in both regions (Table 1).

Respondents were almost equally distributed by gender, with a slightly higher proportion of female users. Users in all age groups accessed their EHR online. Use of the service was higher for people aged 25 to 54 years (ie, citizens in their prime working lives). Access was lower for citizens in the age group over 65 years compared with the general population and those receiving specialist health care (Figure 1).

Only $9.3 \%$ (96/1037) of the respondents had an education at primary or secondary school level. Almost half of the users $(491 / 1037,47.3 \%)$ had an education at university level or higher. About a third of the respondents had a health care professional background.

About half of the respondents described their health status as good, while $18.6 \%(193 / 1037)$ considered themselves to be in poor health. Overall, $90.3 \%$ (937/1037) of the users reported to have sought a doctor (including hospitalizations) at least once in the previous year. 
Table 1. Characteristics of the users.

\begin{tabular}{|c|c|}
\hline Characteristic & Value, $\mathrm{n}(\%)$ \\
\hline \multicolumn{2}{|l|}{ Region $(n=1037)$} \\
\hline Northern Norway & $395(38.1)$ \\
\hline Western Norway & $569(54.9)$ \\
\hline Both regions & $73(7.0)$ \\
\hline \multicolumn{2}{|l|}{ Gender $(n=1037)$} \\
\hline Male & $447(43.1)$ \\
\hline Female & $590(56.9)$ \\
\hline \multicolumn{2}{|l|}{ Age in years $(n=1037)$} \\
\hline $16-24$ & $114(11.0)$ \\
\hline $25-34$ & $232(22.4)$ \\
\hline $35-44$ & $225(21.7)$ \\
\hline $45-54$ & $207(20.0)$ \\
\hline $55-64$ & $152(14.6)$ \\
\hline Over 65 & $107(10.3)$ \\
\hline \multicolumn{2}{|l|}{ Education $(n=1037)$} \\
\hline Primary school & $11(1.1)$ \\
\hline Secondary school & $85(8.2)$ \\
\hline Technical school & $55(5.3)$ \\
\hline High school & $395(38.1)$ \\
\hline University & $475(45.8)$ \\
\hline Doctoral degree & $16(1.5)$ \\
\hline \multicolumn{2}{|c|}{ Health care professional background $(n=1037)$} \\
\hline Yes & $266(25.7)$ \\
\hline No & $771(74.3)$ \\
\hline \multicolumn{2}{|c|}{ Self-reported health $(n=1037)$} \\
\hline Very good & $165(15.9)$ \\
\hline Good & $361(34.8)$ \\
\hline Moderate & $283(27.3)$ \\
\hline $\mathrm{Bad}$ & $159(15.3)$ \\
\hline Very bad & $34(3.3)$ \\
\hline N/A & $35(3.4)$ \\
\hline \multicolumn{2}{|c|}{ Sought a doctor in the past year $(n=1037)$} \\
\hline Yes & $937(90.3)$ \\
\hline No & $64(6.2)$ \\
\hline N/A & $36(3.5)$ \\
\hline \multicolumn{2}{|c|}{ Number of doctor's visits in the past year $(n=702)$} \\
\hline $1-5$ & $365(52.0)$ \\
\hline $6-10$ & $200(28.5)$ \\
\hline $11-20$ & $62(8.8)$ \\
\hline Over 20 & $75(10.7)$ \\
\hline
\end{tabular}


Figure 1. Distribution of users by age groups compared with patients receiving specialist health care and the general population.

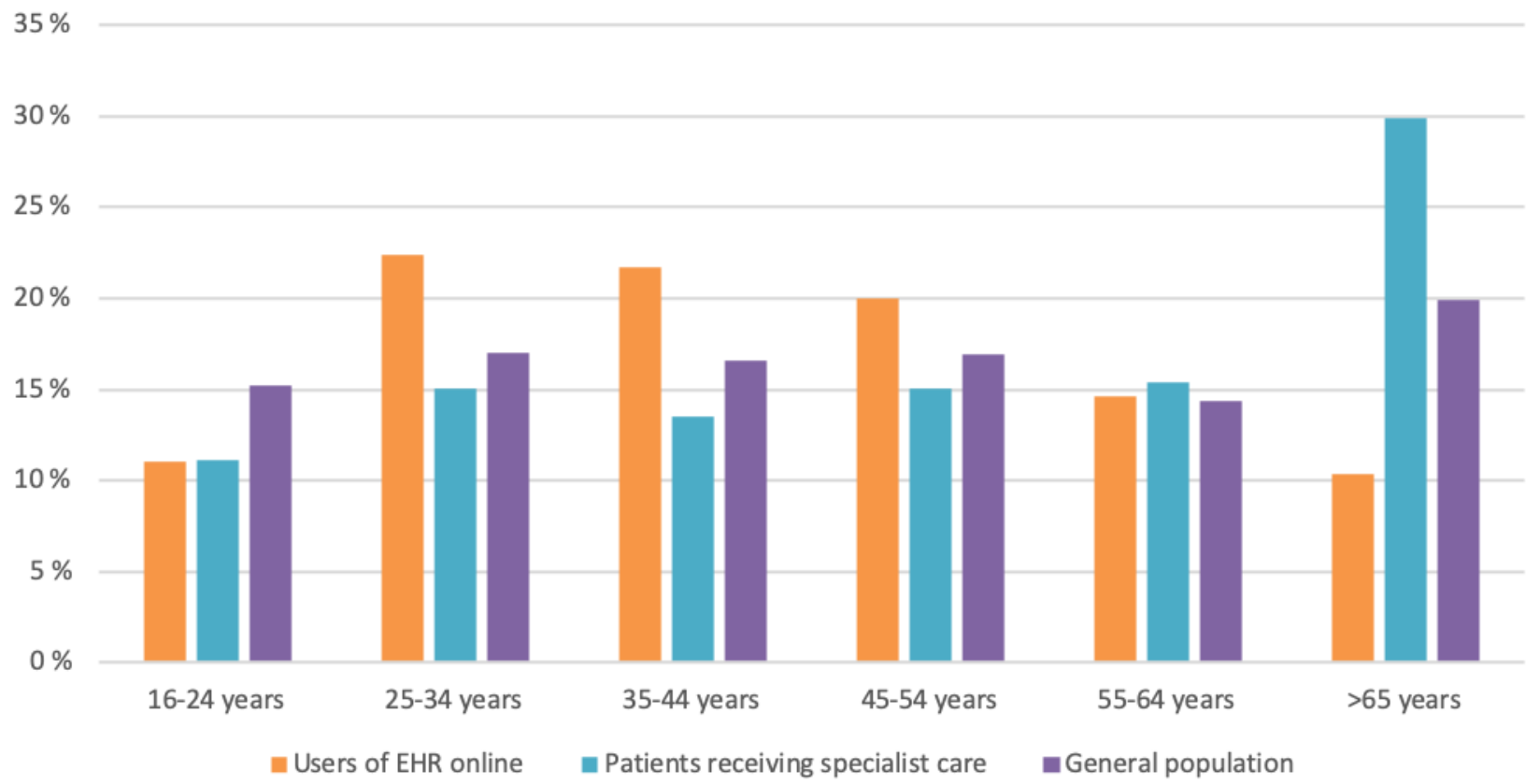

\section{Patient Use of the Service}

About a third of the respondents (305/1037, 29.4\%) accessed their EHR online regularly, and a similar proportion of respondents $(303 / 1037,29.2 \%)$ used the service when necessary (Table 2). The remaining users accessed the service only once or twice. The majority of the users $(601 / 1037,58.0 \%)$ had up to 50 documents available online, while fewer users $(177 / 1037$, $17.0 \%$ ) had more than 50 documents. Only a fourth of the respondents tried the service without having any documents online. About two-thirds $(516 / 778,66.4 \%)$ of those who had documents available had accessed at least $80 \%$ of them.

The vast majority of users accessed their EHRs online to look up health information received from the health care provider $(687 / 778,88.3 \%)$ or to keep track of their treatment $(684 / 778$, $87.9 \%)$. Another important reason for using the service was to prepare for an appointment or a hospital admission. Patients also considered it useful to share documents with their GP, other health care professionals, family, or friends.

Over half of the respondents $(432 / 778,55.5 \%)$ found the service while exploring another section of the national portal [26]. The remaining users became acquainted with the service from other sources, including media, health care professionals, or information provided at the hospital. Contact with service support occurred for $15.3 \%$ (119/778) of the users. Reasons included request to access older documents, report of incorrect or missing information, or need for explanation. Of those who requested older documents, 35.9\% (14/39) obtained access after contacting service support.

The analysis of service utilization against patient characteristics (Table 3) revealed that frequency of access to PAEHR was associated with health region $(P<.001)$, age $(P=.02)$, gender $(P<.001)$, health care professional background $(P=.004)$, self-reported health $(P<.001)$, and attendance to a doctor in the previous year $(P<.001)$. In particular, post hoc tests showed that the proportion of regular users was higher among patients living in Northern Norway, women, those with a health care professional background, patients in moderate to very bad health status, and those who had doctor's visits in the past year. Conversely, the number of light users was higher among patients living in Western Norway, men, citizens aged 16 to 25 years, patients in very good health status, and those who did not seek the doctor during the previous year. Frequency of use was also found to be associated with the number of documents available online $(P<.001)$, with post hoc test showing that the number of light users was higher among those who did not have any documents available online. 
Table 2. Patient use of online access to electronic health records.

\begin{tabular}{|c|c|}
\hline Patient use of the service & Value, $\mathrm{n}(\%)$ \\
\hline \multicolumn{2}{|l|}{ Frequency of use $(n=1037)$} \\
\hline First time & $283(27.3)$ \\
\hline A couple of times & $146(14.1)$ \\
\hline When needed & $303(29.2)$ \\
\hline Regularly & $305(29.4)$ \\
\hline \multicolumn{2}{|l|}{ Number of documents available online $(n=1037)$} \\
\hline None & $259(25.0)$ \\
\hline $1-50$ & $601(58.0)$ \\
\hline $50-99$ & $96(9.2)$ \\
\hline $100-499$ & $60(5.8)$ \\
\hline$>500$ & $21(2.0)$ \\
\hline \multicolumn{2}{|l|}{ Documents opened $(n=778)$} \\
\hline Less than $15 \%$ & $88(11.3)$ \\
\hline $15 \%-49 \%$ & $78(10.0)$ \\
\hline $50 \%-79 \%$ & $96(12.3)$ \\
\hline $80 \%-99 \%$ & $206(26.5)$ \\
\hline $100 \%$ & $310(39.9)$ \\
\hline \multicolumn{2}{|l|}{ Main reasons for using the service $(n=778)$} \\
\hline Look up health information & $687(88.3)$ \\
\hline Keep track of the treatment & $684(87.9)$ \\
\hline Prepare for an appointment or admission & $498(64.0)$ \\
\hline Share documents with $\mathrm{GP}^{\mathrm{a}}$ or other health care professionals & $292(37.5)$ \\
\hline Share documents with family and friends & $194(24.9)$ \\
\hline \multicolumn{2}{|l|}{ Acquaintance with the service $(n=778)$} \\
\hline Helsenorge & $432(55.5)$ \\
\hline Media (newspaper, radio, TV, social media, etc) & $129(16.6)$ \\
\hline Health care professionals & $115(14.8)$ \\
\hline Written information at the hospital & $110(14.1)$ \\
\hline Other & $76(9.8)$ \\
\hline Family or friends & $72(9.3)$ \\
\hline \multicolumn{2}{|l|}{ Contact with service support $(n=778)$} \\
\hline Yes & $119(15.3)$ \\
\hline No & $659(84.7)$ \\
\hline \multicolumn{2}{|l|}{ Availability of older documents $(n=39)$} \\
\hline Yes & $14(35.9)$ \\
\hline No & $25(64.1)$ \\
\hline
\end{tabular}

${ }^{\mathrm{a}} \mathrm{GP}$ : general practitioner. 
Table 3. Association between service utilization and patient characteristics.

\begin{tabular}{|c|c|c|c|}
\hline Patient characteristics & Light user ${ }^{\mathrm{a}}, \mathrm{n}(\%)$ & Regular user $^{\mathrm{b}}, \mathrm{n}(\%)$ & $P$ value \\
\hline Region & & & $<.001$ \\
\hline Northern Norway $(n=395)$ & $129(32.7)$ & $266(67.3)$ & \\
\hline Western Norway $(n=569)$ & $251(44.1)$ & $318(55.9)$ & \\
\hline Gender & & & $<.001$ \\
\hline Male $(n=447)$ & $215(48.1)$ & $232(51.9)$ & \\
\hline Female $(n=590)$ & $214(36.3)$ & $376(63.7)$ & \\
\hline Age in years & & & .02 \\
\hline $16-24(n=114)$ & $63(55.3)$ & $51(44.7)$ & \\
\hline $25-34(n=232)$ & $102(44.0)$ & $130(56.0)$ & \\
\hline $35-44(n=225)$ & $87(38.7)$ & $138(61.3)$ & \\
\hline $45-54(n=207)$ & $79(38.2)$ & $128(61.8)$ & \\
\hline $55-64(n=152)$ & $54(35.5)$ & $98(64.5)$ & \\
\hline Over $65(\mathrm{n}=107)$ & $44(41.1)$ & $63(58.9)$ & \\
\hline Education & & & .48 \\
\hline Primary school $(\mathrm{n}=11)$ & $5(45.5)$ & $6(54.5)$ & \\
\hline Secondary school $(\mathrm{n}=85)$ & $29(34.1)$ & $56(65.9)$ & \\
\hline Technical school $(\mathrm{n}=55)$ & $22(40.0)$ & $33(60.0)$ & \\
\hline High school $(\mathrm{n}=395)$ & $158(40.0)$ & $237(60.0)$ & \\
\hline University $(\mathrm{n}=475)$ & $210(44.2)$ & $265(55.8)$ & \\
\hline Doctoral degree $(n=16)$ & $5(31.3)$ & $11(68.8)$ & \\
\hline Health care professional background & & & .004 \\
\hline Yes $(n=266)$ & $90(33.8)$ & $176(66.2)$ & \\
\hline No $(n=771)$ & $339(44.0)$ & $432(56.0)$ & \\
\hline Self-reported health & & & $<.001$ \\
\hline Very good $(n=165)$ & $109(66.1)$ & $56(33.9)$ & \\
\hline Good $(n=361)$ & $157(43.5)$ & $204(56.5)$ & \\
\hline Moderate $(n=283)$ & $90(31.8)$ & $193(68.2)$ & \\
\hline $\operatorname{Bad}(\mathrm{n}=159)$ & $52(32.7)$ & $107(67.3)$ & \\
\hline Very bad $(n=34)$ & $9(26.5)$ & $25(73.5)$ & \\
\hline Sought a doctor (past year) & & & $<.001$ \\
\hline Yes $(n=937)$ & $354(38.0)$ & $583(62)$ & \\
\hline No $(n=64)$ & $54(84)$ & $10(16)$ & \\
\hline Number of documents available online & & & $<.001$ \\
\hline None $(\mathrm{n}=259)$ & $223(86.1)$ & $36(13.9)$ & \\
\hline $1-50(n=601)$ & $189(31.4)$ & $412(68.6)$ & \\
\hline $50-99(\mathrm{n}=96)$ & $8(8.3)$ & $88(91.7)$ & \\
\hline $100-499(n=60)$ & $6(10.0)$ & $54(90.0)$ & \\
\hline$>500(\mathrm{n}=21)$ & $3(14.3)$ & $18(85.7)$ & \\
\hline
\end{tabular}

${ }^{\mathrm{a}}$ Used the service for the first time/a couple of times.

${ }^{\mathrm{b}}$ Used the service when needed/regularly. 


\section{Patient Experience With the Service}

The vast majority $(965 / 1037,93.1 \%)$ of the users found it easy to access their EHR online (Table 4). Of those users who had difficulties in accessing the service, only $15.3 \%$ (11/72) sought help from family, friends, service support, or health personnel.

About two-thirds of respondents $(476 / 713,66.8 \%)$ expected to have more documents accessible through the service, while only a small percentage of patients $(40 / 703,5.7 \%)$ thought that there were too many documents (Figure 2). There were some difficulties in understanding what all the documents listed in their EHR were about. However, the vast majority of the users $(643 / 755,85.2 \%)$ understood most of the content reported in the documents, despite over half of them $(430 / 733,58.7 \%)$ acknowledging difficulties in understanding some medical terms or phrases. There were also a number of respondents $(199 / 608$, $32.7 \%$ ) who thought that some documents were incomplete. Only a fourth of the users $(99 / 419,23.6 \%)$ encountered technical challenges in saving or printing documents that were available digitally.
Clinical advantages to the patients included a better understanding of their health condition $(565 / 691,81.8 \%)$ and easier control of their health status $(685 / 740,92.6 \%)$. After using the service, most users acknowledged that they felt better prepared for future hospital visits or admissions (571/653, $87.4 \%$ ) and that it became easier to communicate with health care professionals at the hospital $(493 / 618,79.8 \%)$. Patients also experienced increased empowerment. They felt more responsible for their treatment $(413 / 660,62.6 \%)$ and thought that they could better influence its progress $(493 / 674,73.1 \%)$. Only a small proportion of patients $(136 / 707,19.2 \%)$ expressed concerns about the information accessible online. Users also experienced better security $(655 / 730,89.7 \%)$ when accessing their EHR online.

The overall satisfaction with the service was very high (700/755, $92.7 \%$ ). The vast majority of the respondents stated that they would continue accessing their EHR online in the future $(753 / 778,96.8 \%)$ and they recommended the service to others (695/778, 89.3\%; Table 4).

Table 4. Accessibility and patient preferences with online access to electronic health record.

\begin{tabular}{ll}
\hline Patient experience with the service & Value, $\mathrm{n}(\%)$ \\
\hline Ease of access (n=1037) & $559(53.9)$ \\
Very easy & $406(39.2)$ \\
Easy & $52(5.0)$ \\
Difficult & $20(1.9)$ \\
Very difficult & $11(15.3)$ \\
Sought for help (n=72) & $61(84.7)$ \\
Yes & $753(96.8)$ \\
No & $18(2.3)$ \\
Future use of the service (n=778) & $7(0.9)$ \\
Yes & \\
Maybe & $695(89.3)$ \\
No & $72(9.3)$ \\
Recommend the service to others (n=778) & $11(1.4)$ \\
Yes & \\
Maybe & \\
\hline
\end{tabular}


Figure 2. Patient satisfaction with online access to electronic health record.

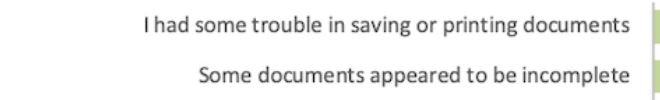

It was difficult to understand what the documents were about

I understood most of what I read

It was difficult to understand some medical terms or phrases

| thought I could access more documents

There were too many documents

It is easier to keep track of my health status

I feel better prepared for an appoitment / admission

It is easier to communicate with healthcare professionals

I feel that I have a better understanding of my health condition

I feel that I can help and influence my treatment

I feel that I get more responsibility for the treatment

I have been worried about information I have received

I experience increased security

I am overall satisfied about the service

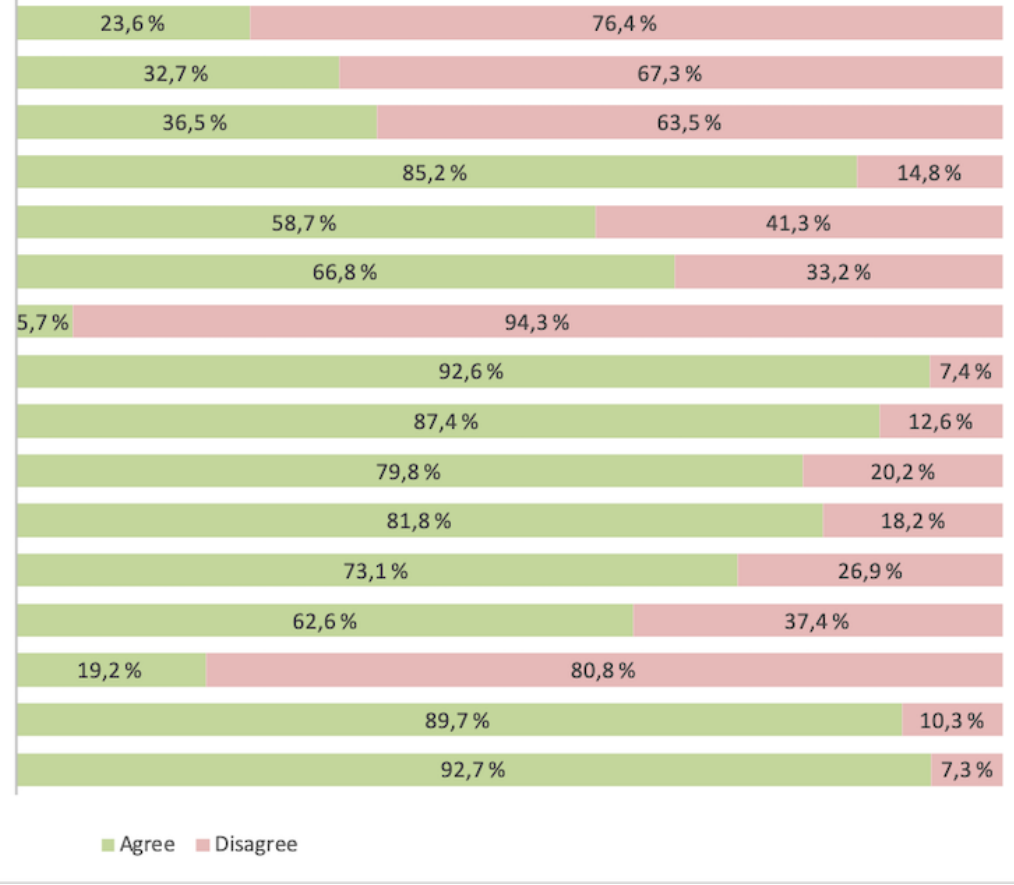

convenience of accessing their EHRs directly from home, where they could easily find all their digital documents in one place and read them in a peaceful environment. The remaining comments were related to positive feedback of a more general nature $(21 / 268,7.8 \%)$, criticism $(16 / 268,6.0 \%)$, or additional information on health status $(5 / 268,1.9 \%)$.

In the second open text field following the question on whether respondents would recommend using the service to others, a total of 208 comments were expressed, most of which were positive opinions (197/208, 94.7\%). Online access to EHRs were described as useful, informative, effective, helpful, easy, practical, and safe.

I think that this service is especially good when you have old parents or very sick family members who do not get all the information when they are at the doctor or at the hospital. A relative can then get permission to read and try to understand the content and follow up with the treatment (for instance, hospitals admissions, etc.). Everything is all gathered here, instead of having papers around your house.

Another advantage perceived by the users was that the PAEHR increased accessibility compared with the traditional practice of requesting a copy of their health records on paper or CD. This, in turn, contributed to improved patient engagement.

\section{Many are interested in what is written in their health record but just not enough to make them ask to get access to it. Through online access it becomes easier for most people to keep themselves up to date on their own health record, as well as on future appointments.}

There were $2.4 \%$ of respondents (5/208) who expressed mixed comments regarding the utility of the service, which could be more or less beneficial depending on the user characteristics (eg, age, computer literacy) as well as their health condition.
There were also 23 comments $(8.6 \%)$ regarding practical benefits of using the service. Patients especially appreciated the 
There were only $2.9 \%$ of comments (6/208) expressing concerns about online access to EHR, some of which was pointed out by users with a health care professional background.

Online access to the health record should not be open
to everyone. Now I think first of all about psychiatric
patients. I think it can be negative and cause distrust
toward health personnel, making them feel like
patients and not like persons (due to the way things
are formulated and professional expressions). Several
of the patients I talk with feel unheard and trust much
less in the treatment and health care providers than
before...Health professionals also express uncertainty
and dissatisfaction with open access to health records.

Finally, 129 comments were provided in the open-ended question included at the end of the survey where users could write additional thoughts. Four common themes were identified after analyzing the content of these answers: availability of documents, information about their health status, technical issues and suggestions for improvement, and experienced satisfaction. There were $36.4 \%$ of comments (47/129) concerning the availability of documents online. Some users missed the chance to access older documents, health records from their GP or other health professionals, documents for their children, laboratory test results, and digital imaging tests. There was also a number of comments about the current lack of documents from the two other health regions which had not yet implemented online access to EHRs. Other respondents reported that they had no or little information visible in their PAEHR. A total of $36.4 \%$ of users (47/129) voluntarily provided comments with general information about their health status. There were 13 users who underwent cancer treatment, and 16 users who referred to the presence of chronic illness, such as rheumatologic diseases and other musculoskeletal conditions. Other comments were related to different long-lasting conditions, health problems under treatment, or simply additional information about the number of visits to the hospital. There were $17.8 \%$ (23/129) comments specifically reporting issues of a technical nature encountered while using the service. Most comments were related to difficulties in opening specific types of documents and file formats, using a mobile phone, logging in, or accessing specific features. Features which could be improved were the possibility of retrieving the access log, marking documents read and unread, and asking to modify or delete documents. Some respondents also suggested new functions. There were, for instance, four users who expressed their wish for a feature where they could register themselves as blood, organ, or body donors. Finally, 9.3\% of comments (12/129) included feedback regarding general satisfaction with the service and its benefits for patients, such as a better understanding of their own health condition. Two users expressed some concerns related to how the communication with health personnel changed after accessing their EHR online.

\section{Discussion}

\section{Principal Findings}

The results obtained from this survey showed that PAEHR in Norway is becoming a mature and useful service. Most of the users accessed their EHR online regularly, for instance when new information became available after a hospital appointment, and read most of the digital documents. The vast majority of the users had at least one doctor's visit in the previous year, meaning that they had digital documents which were recently made available online. There were fewer patients who tried the service for the first time, some of whom did not have any documents accessible. Service utilization for users in Northern Norway was higher than for those in Western Norway, reflecting the earlier implementation of the service in that region.

The findings of this study seemed to be aligned with the most recent version of Andersen's behavioral model used to analyze utilization of health care services based on contextual as well as individual determinants of access to medical care [34]. In particular, the following components were found to affect utilization of the PAEHR: (1) predisposing factors, including demographic characteristics (eg, age, sex), social factors (eg, education), and mental factors (eg, attitudes), and (2) need factors, comprising both perceived need for health services (ie, how people experience their own health) and evaluated need (ie, professional assessments). Enabling factors, including financing (eg, income) and organizational factors (eg, transportation) were not covered by this survey, and therefore no association with service utilization could be explored. In this survey, frequency of access to the PAEHR was found to be associated with self-reported health status, region, gender, age, and health care professional background. The service appeared to be more suitable to patients in need of medical care, especially those in moderate or bad health and greater overall morbidity, as suggested by other studies [11,35]. Patients with multiple chronic conditions have, in fact, significantly higher odds of accessing their records [36]. Despite users in all age groups accessed their EHR online, citizens in the age group over 65 years used the service at a lower degree compared with patients receiving specialist health care and the general population. One explanation is that older patients tend to have a lower computer literacy and thus are less likely to use digital services [37], especially when accessing them for the first time [1]. Another explanation is that older patients are often sicker, with a higher risk of having health conditions that can affect their ability to use technology and interpret digital content $[36,38]$. However, it is suggested that those who can benefit the most from a PAEHR may be the least able to use it [39]. It is therefore important to address this patient group so that more elderly will be able to access their EHRs in the future. About $60 \%$ of those users over 65 years used the service regularly. Most first-time users were found in the age group 16 to 25 years. In our survey, adult females were the most active users of PAEHRs. Similar findings were found in recent large-scale studies [18,21]. One reason might be the general lower consultation rate among men [40]. Users with a health care professional background used the service at a higher degree, confirming the results from the use of PAEHRs in Sweden [18]. In a European study on citizens' use of eHealth services across seven countries, women and people with higher education tended to use the internet more for health purposes [41].

Most respondents indicated that the system was easy to use, confirming the positive findings from other studies on patient 
experience with PAEHRs $[8,29,42,43]$. Two-thirds of the respondents expected to have more documents accessible online. As previously mentioned, not all of the information was digitally available. Health records from GPs, dentists, and other specialists were not yet accessible through the service. Some documents were not made available for technical, legal, or professional reasons. Moreover, only documents generated after the PAEHR was introduced in Northern Norway and Western Norway were available online. Some users also complained about the lack of documents from the two other regions which had not implemented the service. Approximately one-third of all respondents thought that some documents were incomplete. Similar results have been previously reported $[35,43]$. Despite some difficulties in understanding specific medical terms or phrases, the vast majority of the users understood most of the content reported in their EHR, confirming findings from other studies [5,42]. Technical challenges and issues related to security and confidentiality reported in previous studies [29,43,44] affected only a minority of users and did not seem to represent a barrier affecting service utilization. However, some users pointed out a number of technical issues that could be improved and suggested new features that could be added to the service.

Patients using PAEHRs in Norway perceived a number of clinical benefits that were also found in other studies, including enhanced knowledge of their health and improved self-care $[11,21,22,35,42,45]$, greater patient empowerment $[9,21,22]$, and easier communication with health care providers $[11,22,35,42,45]$. The vast majority of the users also experienced increased security [11]. There were, however, a few users who expressed concerns about use of the service by elderly with low computer literacy as well as by patients with severe health conditions, who might prefer accessing new information only after having communicated directly with health personnel. The results obtained from the analysis of the qualitative data confirmed that the PAEHR was particularly useful to patients with complex, long-term, or chronic conditions. Despite some health professionals expecting access to health records to be harmful, patients who choose to look at their documents often find access helpful and reassuring even if the news is bad, such as in cases of cancer care [46]. Through online access it becomes easier for most people to look up health information received from the health care provider [45], take care of their treatment [21], prepare for an appointment or a hospital admission [45], and share documents with someone else [21]. Few users with a health care professional background thought that online access to the health records should not be open to everyone. One respondent, for instance, expressed worries for psychiatric patients, who could feel unheard and trust much less in their health care providers than before. Overall, over $90 \%$ of the users indicated that they would continue using the service in the future and recommend it to others, confirming findings from other studies [18,23,27].

\section{Strengths and Limitations}

With a total of 1037 respondents, this survey is one of the few large-scale studies focusing on patient experience with PAEHRs. We were able to collect a large amount of quantitative data from multiple choice questions and use them to describe the characteristics of the users, patient use of the service, and patient experience with the service. Moreover, quantitative data were used to explore the association between different variables and especially how patient characteristics affected service utilization. However, this was mainly a descriptive survey rather than an explorative study. For a robust investigation of the factors affecting service utilization, a more comprehensive data collection process would be needed. Qualitative information was also collected from three open text fields. A total of 605 comments were analyzed and used to support the quantitative data. Users providing additional comments tend to be those who have very positive or negative experiences. To collect more detailed information on relevant topics, such as patient empowerment, in-depth qualitative interviews with randomly selected users should be conducted in future studies.

Despite the number of respondents, one main limitation of this study is related to its design. Although observational studies and surveys have provided evidence of benefits and satisfaction for patients, there is still little reliable evidence of improved health outcomes from experimental studies [37]. Future evaluations of PAEHRs should focus on specific populations or chronic conditions that are more likely to achieve clinically meaningful benefits and use randomized controlled trials or implementation research methods [37,47].

This was one of the largest surveys conducted on the use of PAEHRs, with respondents from two of the four health regions in Norway. By 2019, online access to EHRs will be offered to citizens in South-Eastern Norway, meaning that an even larger proportion of the population will have access to the service. Patient experience with the service might be influenced by a different level of maturity of the service and therefore vary across regions. For such a wide-scale routine service, whose functionalities might change over time, it is important to implement continuous evaluation programs able to simultaneously evaluate digital health interventions while they are being designed, developed, and deployed [48]. Finally, this survey was limited to patients who accessed the service at least once. Moreover, $25 \%$ of the respondents did not have any documents available online. Future studies might be focused on exploring the reasons why some patients do not use the service.

\section{Conclusions}

We conducted an online survey of users of the PAEHR in Norway. A total of 1037 respondents participated in the survey, most of whom accessed their EHRs online regularly. Service utilization was associated with self-reported health, age, gender, education, and health care professional background. Patients were highly satisfied with the service and found it useful to look up health information, keep track of their treatment, prepare for a hospital appointment, and share documents with their GP or family. Users also experienced clinical benefits from accessing their EHR online, including enhanced knowledge of their health, improved self-care, greater empowerment, easier communication with health care providers, and increased security. Future studies should include both experimental designs focused on specific populations or chronic conditions that are more likely to achieve clinically meaningful benefits and continuous evaluation 
programs to evaluate implementation and changes of wide-scale routine services over time.

\section{Acknowledgments}

We thank the Norwegian Directorate of eHealth for publishing the survey on the national portal.

\section{Authors' Contributions}

PZ contributed to conception and design of the study, acquisition of data, analysis of data, interpretation of data, and drafting and revision of the manuscript. PEK contributed to analysis of data, interpretation of data, and revision of the manuscript. TS contributed to conception and design of the study, interpretation of data, and revision of the manuscript. MAJ contributed to conception and design of the study, interpretation of data, and revision of the manuscript. All authors read and approved the final manuscript.

\section{Conflicts of Interest}

None declared.

\section{Multimedia Appendix 1}

Online survey (in Norwegian).

[PDF File (Adobe PDF File), 46 KB-Multimedia Appendix 1]

\section{References}

1. Tieu L, Schillinger D, Sarkar U, Hoskote M, Hahn KJ, Ratanawongsa N, et al. Online patient websites for electronic health record access among vulnerable populations: portals to nowhere? J Am Med Inform Assoc 2017 Apr 01;24(E1):E47-E54. [doi: 10.1093/jamia/ocw098] [Medline: 27402138]

2. White H, Gillgrass L, Wood A, Peckham DG. Requirements and access needs of patients with chronic disease to their hospital electronic health record: results of a cross-sectional questionnaire survey. BMJ Open 2016 Oct 14;6(10):e012257 [FREE Full text] [doi: 10.1136/bmjopen-2016-012257] [Medline: 27742623]

3. Ross SE, Todd J, Moore LA, Beaty BL, Wittevrongel L, Lin C. Expectations of patients and physicians regarding patient-accessible medical records. J Med Internet Res 2005;7(2):e13 [FREE Full text] [doi: 10.2196/jmir.7.2.e13] [Medline: 15914460]

4. Delbanco T, Walker J, Darer JD, Elmore JG, Feldman HJ, Leveille SG, et al. Open notes: doctors and patients signing on. Ann Intern Med 2010 Jul 20;153(2):121-125. [doi: 10.7326/0003-4819-153-2-201007200-00008] [Medline: 20643992]

5. Pyper C, Amery J, Watson M, Crook C, Thomas B. Patients' access to their online electronic health records. J Telemed Telecare 2002;8 Suppl 2:103-105. [doi: 10.1177/1357633X020080S247] [Medline: 12217158]

6. Ammenwerth E, Schnell-Inderst P, Hoerbst A. The impact of electronic patient portals on patient care: a systematic review of controlled trials. J Med Internet Res 2012;14(6):e162 [FREE Full text] [doi: 10.2196/jmir.2238] [Medline: 23183044]

7. Wiljer D, Urowitz S, Apatu E, DeLenardo C, Eysenbach G, Harth T, et al. Patient accessible electronic health records: exploring recommendations for successful implementation strategies. J Med Internet Res 2008;10(4):e34 [FREE Full text] [doi: $10.2196 /$ jmir.1061] [Medline: 18974036 ]

8. de Lusignan S, Mold F, Sheikh A, Majeed A, Wyatt JC, Quinn T, et al. Patients' online access to their electronic health records and linked online services: a systematic interpretative review. BMJ Open 2014;4(9):e006021 [FREE Full text] [doi: 10.1136/bmjopen-2014-006021] [Medline: 25200561]

9. Jilka SR, Callahan R, Sevdalis N, Mayer EK, Darzi A. "Nothing about me without me": an interpretative review of patient accessible electronic health records. J Med Internet Res 2015;17(6):e161 [FREE Full text] [doi: 10.2196/jmir.4446] [Medline: 26123476]

10. Winkelman WJ, Leonard KJ, Rossos PG. Patient-perceived usefulness of online electronic medical records: employing grounded theory in the development of information and communication technologies for use by patients living with chronic illness. J Am Med Inform Assoc 2005;12(3):306-314 [FREE Full text] [doi: 10.1197/jamia.M1712] [Medline: 15684128]

11. Mold F, de Lusignan S, Sheikh A, Majeed A, Wyatt JC, Quinn T, et al. Patients' online access to their electronic health records and linked online services: a systematic review in primary care. Br J Gen Pract 2015 Mar;65(632):e141-e151 [FREE Full text] [doi: 10.3399/bjgp15X683941] [Medline: 25733435]

12. Shah SGS, Fitton R, Hannan A, Fisher B, Young T, Barnett J. Accessing personal medical records online: a means to what ends? Int J Med Inform 2015 Feb;84(2):111-118 [FREE Full text] [doi: 10.1016/j.ijmedinf.2014.10.005] [Medline: 25453275]

13. Ålander T, Scandurra I. Experiences of healthcare professionals to the introduction in Sweden of a public ehealth service: patients' online access to their electronic health records. Stud Health Technol Inform 2015;216:153-157. [Medline: 26262029]

14. Workshop: patients' digital access to their health record: a service for all?. URL: http://2016.ehin.no/ workshop-patients-digital-access-to-their-health-record-a-service-for-all/ [accessed 2018-10-31]

15. Essén A, Scandurra I, Gerrits R, Humphrey G, Johansen M, Kierkegaard P, et al. Patient access to electronic health records: differences across ten countries. Health Policy Technol 2018;7:44-56 [FREE Full text] [doi: 10.1016/j.hlpt.2018.04.001] 
16. Hägglund M, Moll J, Åhlfeldt R, Scandurra I. Timing it right—patients' online access to their record notes in Sweden. Stud Health Technol Inform 2018;247:336-340. [Medline: 29677978]

17. Hägglund M, Scandurra I. Patients' online access to electronic health records: current status and experiences from the implementation in Sweden. Stud Health Technol Inform 2017;245:723-727. [Medline: 29295193]

18. Moll J, Rexhepi H, Cajander A, Grünloh C, Huvila I, Hägglund M, et al. Patients' experiences of accessing their electronic health records: national patient survey in Sweden. J Med Internet Res 2018 Nov 01;20(11):e278 [FREE Full text] [doi: 10.2196/jmir.9492] [Medline: 30389647]

19. Leveille SG, Walker J, Ralston JD, Ross SE, Elmore JG, Delbanco T. Evaluating the impact of patients' online access to doctors' visit notes: designing and executing the OpenNotes project. BMC Med Inform Decis Mak 2012 Apr 13;12:32 [FREE Full text] [doi: 10.1186/1472-6947-12-32] [Medline: 22500560]

20. Delbanco T, Walker J, Bell SK, Darer JD, Elmore JG, Farag N, et al. Inviting patients to read their doctors' notes: a quasi-experimental study and a look ahead. Ann Intern Med 2012 Oct 2;157(7):461-470 [FREE Full text] [doi: 10.7326/0003-4819-157-7-201210020-00002] [Medline: 23027317]

21. Walker J, Leveille S, Bell S, Chimowitz H, Dong Z, Elmore JG, et al. OpenNotes after 7 years: patient experiences with ongoing access to their clinicians' outpatient visit notes. J Med Internet Res 2019 May 06;21(5):e13876 [FREE Full text] [doi: 10.2196/13876] [Medline: 31066717]

22. Woods SS, Schwartz E, Tuepker A, Press NA, Nazi KM, Turvey CL, et al. Patient experiences with full electronic access to health records and clinical notes through the My HealtheVet Personal Health Record Pilot: qualitative study. J Med Internet Res 2013;15(3):e65 [FREE Full text] [doi: 10.2196/jmir.2356] [Medline: 23535584]

23. Nazi KM, Hogan TP, McInnes DK, Woods SS, Graham G. Evaluating patient access to Electronic Health Records: results from a survey of veterans. Med Care 2013 Mar;51(3 Suppl 1):S52-S56. [doi: 10.1097/MLR.0b013e31827808db] [Medline: 23407012]

24. Pearce C, Bainbridge M. A personally controlled electronic health record for Australia. J Am Med Inform Assoc 2014;21(4):707-713 [FREE Full text] [doi: 10.1136/amiajnl-2013-002068] [Medline: 24650635]

25. [Kapittel 5. Rett til journalinnsyn]. URL: https://lovdata.no/dokument/NL/lov/1999-07-02-63\#KAPITTEL_6 [accessed 2019-12-22]

26. Helsenorge. URL: https://helsenorge.no/ [accessed 2019-12-22]

27. Sørensen T, Johansen MA. Developing and implementing patients' full-scale electronic access to their health record. Stud Health Technol Inform 2016;228:85-89. [Medline: 27577347]

28. Helse-og Omsorgsdepartementet. 2012. [Én innbygger ? én journal. Digitale tjenester i helse- og omsorgssektoren] URL: https://www.regjeringen.no/contentassets/33a159683925472aa15ad74f27ad04cc/no/pdfs/stm201220130009000dddpdfs. pdf [accessed 2019-12-22]

29. Bartlett C, Simpson K, Turner AN. Patient access to complex chronic disease records on the Internet. BMC Med Inform Decis Mak 2012;12:87 [FREE Full text] [doi: 10.1186/1472-6947-12-87] [Medline: 22867441]

30. Wangberg SC, Andreassen HK, Prokosch H, Santana SMV, Sørensen T, Chronaki CE. Relations between Internet use, socio-economic status (SES), social support and subjective health. Health Promot Int 2008 Mar;23(1):70-77 [FREE Full text] [doi: 10.1093/heapro/dam039] [Medline: 18083686]

31. Subramanian SV, Huijts T, Avendano M. Self-reported health assessments in the 2002 World Health Survey: how do they correlate with education? Bull World Health Organ 2010 Feb;88(2):131-138 [FREE Full text] [doi: 10.2471/BLT.09.067058] [Medline: 20428370]

32. Eysenbach G. Improving the quality of Web surveys: the Checklist for Reporting Results of Internet E-Surveys (CHERRIES). J Med Internet Res 2004 Sep 29;6(3):e34 [FREE Full text] [doi: 10.2196/jmir.6.3.e34] [Medline: 15471760]

33. Hsieh H, Shannon SE. Three approaches to qualitative content analysis. Qual Health Res 2005 Nov;15(9):1277-1288. [doi: 10.1177/1049732305276687] [Medline: 16204405]

34. Andersen R, Davidson P. Improving access to care in America: individual and contextual indicators. In: Andersen RM, Rice TH, Kominski EF, editors. Changing the U.S. Health Care System: Key Issues in Health Services, Policy, and Management. 2nd Edition. San Francisco: Jossey-Bass; 2001.

35. Bhavnani V, Fisher B, Winfield M, Seed P. How patients use access to their electronic GP record-a quantitative study. Fam Pract 2011 Apr;28(2):188-194 [FREE Full text] [doi: 10.1093/fampra/cmq092] [Medline: 21084568]

36. Greenberg AJ, Falisi AL, Finney RLJ, Chou WS, Patel V, Moser RP, et al. Access to electronic personal health records among patients with multiple chronic conditions: a secondary data analysis. J Med Internet Res 2017 Jun 02;19(6):e188 [FREE Full text] [doi: 10.2196/jmir.7417] [Medline: 28576755]

37. Archer N, Fevrier-Thomas U, Lokker C, McKibbon KA, Straus SE. Personal health records: a scoping review. J Am Med Inform Assoc 2011;18(4):515-522 [FREE Full text] [doi: 10.1136/amiajnl-2011-000105] [Medline: 21672914]

38. Sakaguchi-Tang DK, Bosold AL, Choi YK, Turner AM. Patient portal use and experience among older adults: systematic review. JMIR Med Inform 2017 Oct 16;5(4):e38 [FREE Full text] [doi: 10.2196/medinform.8092] [Medline: 29038093]

39. Kim E, Stolyar A, Lober WB, Herbaugh AL, Shinstrom SE, Zierler BK, et al. Challenges to using an electronic personal health record by a low-income elderly population. J Med Internet Res 2009;11(4):e44 [FREE Full text] [doi:

10.2196/jmir.1256] [Medline: 19861298] 
40. Wang Y, Hunt K, Nazareth I, Freemantle N, Petersen I. Do men consult less than women? An analysis of routinely collected UK general practice data. BMJ Open 2013;3(8):e003320 [FREE Full text] [doi: 10.1136/bmjopen-2013-003320] [Medline: 23959757]

41. Andreassen HK, Bujnowska-Fedak MM, Chronaki CE, Dumitru RC, Pudule I, Santana S, et al. European citizens' use of E-health services: a study of seven countries. BMC Public Health 2007;7:53 [FREE Full text] [doi: 10.1186/1471-2458-7-53] [Medline: 17425798$]$

42. Pyper C, Amery J, Watson M, Crook C. Patients' experiences when accessing their on-line electronic patient records in primary care. Br J Gen Pract 2004 Jan;54(498):38-43 [FREE Full text] [Medline: 14965405]

43. Hassol A, Walker JM, Kidder D, Rokita K, Young D, Pierdon S, et al. Patient experiences and attitudes about access to a patient electronic health care record and linked web messaging. J Am Med Inform Assoc 2004;11(6):505-513 [FREE Full text] [doi: 10.1197/jamia.M1593] [Medline: 15299001]

44. Masys D, Baker D, Butros A, Cowles KE. Giving patients access to their medical records via the internet: the PCASSO experience. J Am Med Inform Assoc 2002;9(2):181-191 [FREE Full text] [Medline: 11861633]

45. Mold F, de Lusignan S. Patients' online access to their primary care electronic health records and linked online services: implications for research and practice. J Pers Med 2015 Dec 04;5(4):452-469 [FREE Full text] [doi: 10.3390/jpm5040452] [Medline: 26690225]

46. Fisher B, Britten N. Patient access to records: expectations of hospital doctors and experiences of cancer patients. Br J Gen Pract 1993 Feb;43(367):52-56 [FRE Full text] [Medline: $\underline{\text { 8466775] }}$

47. Zanaboni P, Ngangue P, Mbemba GIC, Schopf TR, Bergmo TS, Gagnon M. Methods to evaluate the effects of internet-based digital health interventions for citizens: systematic review of reviews. J Med Internet Res 2018 Jun 07;20(6):e10202 [FREE Full text] [doi: 10.2196/10202] [Medline: 29880470]

48. Catwell L, Sheikh A. Evaluating eHealth interventions: the need for continuous systemic evaluation. PLoS Med 2009 Aug;6(8):e1000126 [FREE Full text] [doi: 10.1371/journal.pmed.1000126] [Medline: 19688038]

\author{
Abbreviations \\ CHERRIES: Checklist for Reporting Results of Internet E-Surveys \\ EHR: electronic health record \\ GP: general practitioner \\ PAEHR: patient-accessible electronic health record
}

Edited by G Eysenbach; submitted 05.09.19; peer-reviewed by M Hägglund, R Dendere, T Risling, M De Wit; comments to author
25.09.19; revised version received 04.11.19; accepted 16.12.19; published 07.02.20
Please cite as:
Zanaboni P, Kummervold PE, Sørensen T, Johansen MA
Patient Use and Experience With Online Access to Electronic Health Records in Norway: Results From an Online Survey
J Med Internet Res 2020;22(2):e16144
URL: $\underline{\text { https://www.jmir.org/2020/2/e16144 }}$
doi: $10.2196 / 16144$
PMID: $\underline{32031538}$

CPaolo Zanaboni, Per Egil Kummervold, Tove Sørensen, Monika Alise Johansen. Originally published in the Journal of Medical Internet Research (http://www.jmir.org), 07.02.2020. This is an open-access article distributed under the terms of the Creative Commons Attribution License (https://creativecommons.org/licenses/by/4.0/), which permits unrestricted use, distribution, and reproduction in any medium, provided the original work, first published in the Journal of Medical Internet Research, is properly cited. The complete bibliographic information, a link to the original publication on http://www.jmir.org/, as well as this copyright and license information must be included. 